\title{
Erken Cumhuriyet Türkiyesi’nde Yapı Malzemesi Endüstrisi ve Mimari Üretim/Kültür Ortamı
}

\author{
Building Materials Industry and Architectural \\ Practice/Culture in Early Republican Turkey
}

Yekta ÖZGÜVEN, ๑ Emel CANTÜRK

ÖZ

Cumhuriyet'in ilanıyla birlikte benimsenen ve başta toplumsal, kültürel, ekonomik ve politik olmak üzere her alanda köklü değişimlere yol açan "çağdaşlaşma" idealinin somutlaştığı en önemli alanlardan biri mimari üretim ve kültür ortamı olmuş; bu idealin gerçekleştirilmesi, çağdaşlaşmanın fiziksel görünürlük kazanacağı modern kentlerin inşası ile ilişkilendirilmiştir. Bu kapsamda, başta Ankara olmak üzere, tüm Anadolu kentlerinde kapsamlı imar faaliyetlerinin başlatılması, modern yapı malzemelerine yönelik talebi artırmış; ancak Cumhuriyet Türkiyesi'nin, İmparatorluk'tan devralmış olduğu kısıtlı ve gelişmemiş yapı malzemeleri endüstrisinin bu ihtiyacın gereklerini karşılayacak düzeyde olmaması nedeniyle, erken Cumhuriyet yılları, yapı malzeme endüstrisinin Cumhuriyet'in sanayileşme politikaları kapsamında yapılandırılma çalışmalarına sahne olmuştur. Yalnızca mimarlık ortamı ile değil; olumlu ve/veya olumsuz sonuçları tüm dünyada etkili olan tarihsel kırılmalar ile ilişkili olarak alınan çeşitli yönetsel kararlar ve gerçekleştirilen uygulamalarla şekillenen bu yapılandırma çalışmaları ise, yapı malzemesi endüstrisinin gelişiminde olduğu gibi, dönemin yapı üretiminde de belirleyici rol oynamıştır. Bu bağlamda, bu çalışma ile erken Cumhuriyet döneminde yapı malzemesi endüstrisindeki gelişmeler, bu gelişmelerin mimarlık ortamındaki yansımaları ve yapı malzemesi endüstrisi ile mimari kültür ve üretim ortamı arasındaki karşılıklı ilişkiler, dönemin önemli eşikleri üzerinden tarihsel bir okuma aracılığıyla ortaya konmaktadır. Yapı malzemesi endüstrisinin süreç içerisindeki gelişiminin, yapı malzemelerinin teknik nitelikleri dışında, dönemi içerisinden ve dönemin içsel dinamiklerine dayanan bir anlatıyla ele alındığı bu çalışma ile, konu ile ilgili kuramsal bir tartışma zemini oluşturulması ve literatüre katkı sağlanması hedeflenmektedir.

Anahtar sözcükler: Erken Cumhuriyet dönemi; mimari üretim ve kültür ortamı; sanayileşme politikaları; yapı malzemesi endüstrisi.

\section{ABSTRACT}

The medium of the architectural practice and culture has been one of the most significant domains, that the ideology of "modernization" adopted by the proclamation of the Republic leading to vast social, cultural, economic and political changes, embodied in. And the realization of this ideal has been associated with the construction of modern cities in which modernization would become physically visible. In this context, the initiation of comprehensive construction activities in all Anatolian cities, especially in Ankara, has increased the demand for modern building materials. However, due to the fact that the inadequate and undeveloped building materials industry that has been inherited from the Empire, the early Republican years have witnessed the structuring of the building materials industry within the scope of the Republic's industrialization policies. This structuring process, which has been shaped by various administrative decisions and practices in relation not only to the architectural medium; but also to the historical breakthroughs have positive and/or negative consequences all over the world. These breakthroughs and consequences have played a deterministic role in building production of the period, as well as the development of the building materials industry. In this context, this article reveals the developments in the building materials industry during the early Republican period, the reflections of these developments on the architectural domain and the interrelationship between the building materials industry and medium of the architectural culture and practice, through a historical reading on the important thresholds of the period. The aim of the article is to create a theoretical discussion on the subject and to contribute to the literature, by introducing the development of the building material industry on a narrative that is based on the internal dynamics of the period, instead of focusing the technical qualities of the building materials.

Keywords: Early Republican period; architectural practice and culture; industrialization policies; building materials industry.

Maltepe Üniversitesi Mimarlık ve Tasarım Fakültesi, Mimarlık İngilizce Bölümü, İstanbul

Başvuru tarihi: 01 August 2018 - Kabul tarihi: 10 September 2019

İletişim: Yekta ÖZGÜVEN. e-posta: ozguven.yekta@gmail.com

○ 2019 Yıldız Teknik Üniversitesi Mimarlık Fakültesi - @ 2019 Yıldız Technical University, Faculty of Architecture 


\section{Giriş}

Mimarlık pratiği; üreticisi ve kullanıcısı olan aktörler, tasarım düşüncesi, sonuç ürün olan yapının kendisi ve üretim sürecini oluşturan inşai faaliyet, yapının üretildiği dönemin ve yerin özellikleri ile yapıyı oluşturan malzemeler gibi çeşitli bileşenlerin oluşturduğu bir bütündür. Bu bileşenler, mimarlık yazınında çeşitli çalışmalara konu edilmiş olmakla birlikte, yapı malzemeleri ile ilgili çalışmaların, çoğunlukla malzemenin dayanımı ve yapısal özellikleri gibi teknik niteliklerine odaklandığı görülür. Bu bağlamda, yapı malzemelerinin ne mimarlık eğitimi, ne de mimarlık yazınında teorik tartışmalara konu edilmemiş olması ve daha çok mimarlıkmühendislik disiplinlerinin arakesitinde incelenmiş olması dikkat çekicidir.

Oysa, sürekli bir değişim ve ilerleme içerisinde olan yapı malzemesi endüstrisi, mimari üretimi olanaklı kılan en önemli girdilerden birini tanımlar. Dolayısıyla, yapı malzemesi endüstrisinin süreç içerisindeki gelişiminin, mimari kültür ve pratik ortamını doğrudan etkilediği söylenebilir. Bu doğrultuda, bu çalışma ile, yapı malzemesi endüstrisindeki gelişmelerin tarihsel bir okuma aracılığıyla ortaya konması ve bu gelişmelerin mimarlık ortamındaki yansımalarının irdelenmesi, yapı malzemeleri ile mimari kültür ve üretim ortamı arasındaki karşılıkı ilişkilerin açığa çıkarılması ve görünür kılınması hedeflenmektedir. Konunun böylesi yeni bir bakış açısıyla ele alınması, mimarlık yazınına önemli bir katkı sağlayacağı gibi, gelecekte yapılacak çalışmaların arttırılması için de bir tartı̧̧ma zemini oluşturacaktr.

Cumhuriyet'in ilanını izleyen birkaç on yılda, her alanda yürütülen gelenekselden kopma ve modernleşme ideolojisi, mimarlık alanında da kendini göstermiş; mimarlık pratiği de, bu modernleşme hedefi doğrultusundaki kurumsallaşmanın bir parçası olarak yeniden biçimlenmiştir. Bu yeniden biçimlenmenin sonucu ise, mimari etkinlik alanında, gerek düşünce sistemleri, gerek mimari üretim, gerekse de örgütlenme biçimleri bağlamında kapsamlı dönüşümlerin gerçekleşmesi olmuştur. Diğer taraftan, toplumsal hareketliliğin daha önce hiç olmadığı kadar artarak, kentleşmenin farklı bir yönelim kazandığı ve çok partili siyasal döneme geçilen 1950'ler, bu dönüşümlerin başka bir biçime evrileceği önemli bir eşiği tanımlar. Bu doğrultuda, 1923 ile 1950 yılları arası, mimarlık tarihi yazınında, ortak bir modernleşme ideolojisi çerçevesinde "erken Cumhuriyet dönemi" olarak adlandırılmaktaysa da; ${ }^{1}$ söz konusu aralığın bir bütün olarak anlamlandırılabilecek, kültürel, politik ve toplumsal bir süreklilik içermediğini de göz önünde bulundurmak gerekir.

\footnotetext{
Tekeli, İstanbul'un modernleşme tarihini dört aşamaya ayırdığı kronolojik sınıflamasında, Cumhuriyet'in ilan edildiği 1923 yılından, çok partili siyasal hayata geçilen 1950 yılına kadar olan dönemi "kökten modernite dönemi" olarak adlandırır (Tekeli, 2009, s. 11).
}

Bu bağlamda, makalenin kapsamını, erken Cumhuriyet Türkiyesi'ndeki yapı malzemesi endüstrisinin yapılandırılma sürecinin, mimari kültür ve üretim ortamını nasıl şekillendirdiğini, dönemin toplumsal, ekonomik ve kültürel arka planı üzerinden bir okumayla, tarihsel açıdan incelemek oluşturmaktadır. Bu amaçla, çalışmanın tarihsel aralığı 1923-1950 yılları ile sınırlandırılmış olsa da; başta yeni başkent Ankara olmak üzere, kentlerin imarının ve modern yapı üretiminin ancak 1930 'larla birlikte tüm ülkede yaygın biçimde uygulanır ve görünür olması, dolayısıyla yapı malzemesi endüstrisi üzerinden detaylı bir okumanın da 1930 'lu yılların başından itibaren olanaklı hale gelmesi nedeniyle, 1930-1950 yılları arasında yapı malzemesi endüstrisinin mimarlık ortamıyla ilişkisi temel odak noktası olarak belirlenmiştir. Bu doğrultuda, 1923-1950 yılları arasında yapı malzeme endüstrisindeki ve mimarlık ortamındaki gelişmeler, söz konusu tarihsel aralığın toplumsal, kültürel, politik, ekonomik yapılarını belirleyen kendi içsel dinamikleri bağlamında -erken evre, ikinci evre ve çözülme evresi olmak üzere- üç farklı evrede ele alınmıştır.

\section{Erken Evre: İmparatorluk'tan Devralınan Yapı Malzemesi Endüstrisi ve Mimarlık Ortamı}

Kurumsal inşa süreci olarak tanımlanabilecek bu evrenin temel dinamiklerini belirleyen, savaştan yeni çıkmış bir ülke olmanın getirdiği ekonomik imkânsızlıklar ve kuruluş yıllarında yaşanan sıkıntılar olmuştur. Bu bağlamda, Cumhuriyet'in kuruluşundan, mimarlık ortamında önemli dönüşümlere yol açacak gelişmelerin yaşandığı 1930'lara kadar sürecek olan bu dönemde, daha çok yönetsel ve kurumsal anlamda modernleşme ön plandadır. Eski başkent İstanbul'un geri planda kaldığı ve dolayısıyla inşaat yatırımlarının neredeyse tamamen durduğu, yeni başkent Ankara'nın ise henüz modern mimari anlamında imarına başlanmadığı bu dönemde, yapı üretiminin devletin öncelikli yatrım alanlarından biri olmamasıyla da ilintili olarak, ülkede kapsamlı bir yapı üretimi etkinliğinden bahsetmek olanaklı değildir. Bu imar faaliyetlerinin gerçekleştirilmesi ve çağdaşlaşmanın simgesi olarak modern kentlerin inşa edilebilmesi için, öncelikle gerekli altyapıyı tanımlayacak olan kurumsal inşa sürecinin tamamlanmasına odaklanılır. Dolayısıyla, ülkenin kalkınması ve çağdaşlaşmasını sağlayacak en temel dinamiklerden biri olan sanayileşme alanında yeni düzenlemeler yapılarak, çeşitli adımlar atılır. Yerli bir sanayinin oluşturulması amacıyla atılan bu adımlar, yapı malzemesi endüstrisinin yapılandırılmasında da belirleyici olacakttr.

Kuruluş yıllarında, ülke ölçeğinde, ulaşım ağlarının inşa$\mathrm{SI}^{2}{ }^{2}$ altyapı gereksinimleri, savaşta zarar gören alanların yeniden imar edilmesi ve yeni yerleşim alanlarının kurulması gibi yalnızca zorunlu ve fonksiyonel yatırımlara öncelik verilmiştir. $^{3}$ Bu bağlamda, kayda değer yapı etkinlikleri, yeni başkent Ankara'daki kamuya ait "öncelikli" yapılarla sınırlı 
(a)



(b)



(c)



Şekil 1. (a) İkinci TBMM Binası, Vedat Tek, 1926 (www.cumhuriyetmuzesi.gov.tr); (b) Sağlık Bakanlığı, T. Jost, 1927 (Anonim); (c) Genel Kurmay Başkanlığı, C. Holzmeister, 1930 (www.arkitera.com).

kalmıştır (Şekil 1). Cumhuriyet'in ilanıyla birlikte yeni açılan belli başlı kurumlara ait olan bu yapılar, aynı zamanda henüz kırsal bir görünüme sahip olan başkent Ankara'da yeni kurulan Cumhuriyet'in de gücünü simgeleyeceklerdir. Ulusal mimarlık izlerini taşıyan Vedat Tek'in II. Meclis, G. Mongeri'nin Osmanlı Bankası, Ziraat Bankası ve İş Bankası, başkente gelen yabancı devlet adamlarının konaklamaları için yapılan Vedat Tek ve Kemaleddin Bey'in Ankara Palas Oteli, modern mimarinin Türkiye'deki ilk yapısı olan T. Jost'un Sağılı Bakanlığı, milli bir müze kurma amacıyla yapılan Etnografya Müzesi, eski Ankara evlerinden esinlenerek ve yığma bir yapı olmasına rağmen Ankara'da ilk kez olmak üzere bazı kemerlerinde betonarme kullanılan Türk Ocağı gibi yapılar, dönemin öncelikli kurumsallaşma ve yatırım alanlarını da gösterir.

Zaten bu dönemde, Imparatorluk'tan devralınan yapı malzemesi endüstrisinin niteliği de, kapsamlı inşai faaliyetlerin gerçekleştirilmesine olanak sağlayacak durumda değildir. İhtiyacın yalnızca üçte birini karşılayacak üretimi gerçekleştirebilen birkaç çimento, tuğla ve kereste fabrikası ile sınırlı olan yapı malzemesi endüstrisi nedeniyle; bu dönemdeki mimari üretim, tamamen yapı malzemelerinin ithaline bağımlıdır. 40.000 ton/yıl civarında çimento üreten -Darıca Fabrikası ve Eskihisar Fabrikası olmak üzeremevcut iki fabrika, ülke genelindeki ihtiyacın ancak \%20 'sine cevap verebilmekte; ${ }^{5}$ bu nedenle Anadolu kentlerine Rusya, Fransa, İtalya, Romanya ve Almanya gibi yakın Avrupa ülkelerinden çimento ithal edilmektedir. ${ }^{6}$ Dolayısıyla bu yıllarda, başta çimento olmak üzere modern yapı malze-

\footnotetext{
Bu dönemde demiryollarının inşası devletin en fazla yatırım yaptiğı alanlardan biridir ve bu kapsamlı inşa faaliyeti, Başbakanlık Cumhuriyet Arşivi'nde yer alan çok sayıdaki belgeden de anlaşıldığı üzere, büyük miktarda yapı malzemesi gerektirmesi sebebiyle, başta çimento ve demir olmak üzere, yapı malzemesi ithalatının büyük bir kısmını oluşturur. Konu ile ilgili bazı belgeler için bkz. "Anadolu-Bağdat Demiryolları İdaresi'nin ihtiyacı olan 500 ton çimentonun yurtdışından satın alınması" (BCA, 30-18-1-1/18-28-11, 04.05.1926), “Ankara-Sivas Demiryolu İdaresi için gerekli olan çimen-
}

tonun uygun olduğu takdirde yerli talibinden, uygun olmadığı takdirde Avrupa'dan ithali" (BCA, 30-18-11/13-31-15, 13.05.1925), "SamsunÇarşamba demiryolu inşaat için gerekli çimentonun yurtdışından satın alınması" (BCA, 30-18-1-1/17-89-1 31.01.1926), "Yenice-Nusaybin demiryollarını genişletme ve ikma inşaat için gerekli çimentonun ithaline izin verilmesi" (BCA, 30-18-1-1) 24-30-4, 11.05.1927)

Aslanoğlu, 2010, s. 27; Batur, 1998, s. 210

Batur, 1998, s. 210

Sey, 1998, s. 26

Selah, 1934, s. 155.

melerinin kullanımına dayanan betonarme yapım tekniğinin tanımladığı modern mimarinin henüz yaygın uygulama alanı bulduğundan söz edilemediği gibi; neredeyse tüm yapı malzemelerinin ithal edilmesi nedeniyle, mimarlık pratiğini belirleyen de ithalat ve sanayileşme olanaklarıdır.

Çağdaşlaşma ve modernleşmenin, ancak modern bir endüstrinin kurulmasıyla sağlanacağı düşüncesiyle, bu yıllarda sanayiyi geliştirme amacıyla alınan yönetsel kararlar önemli yer tutar. Bunlardan ilki, yerli sanayiyi geliştirmek amacıyla 1927 yılında çıkarılan ve 1942 yılına kadar uygulanan, aynı zamanda yapı malzemesi endüstrisinin gerçekleştirilmesine yönelik atılan ilk adım olan Teşvik-i Sanayi Kanunu'dur. ${ }^{7}$ Bu kanun, özel girişimlere yapı malzemesi fabrikaları açmaları için devlet tarafindan arsa sağlanması ve bu girişimlerin ülke sınırları içerisinde yeterli miktarda veya hiç üretilmeyen yapı malzemelerinin ithali sırasında vergiden muaf tutulmalarının yanı sıra, ${ }^{8}$ önceden beri ithal edilen yapı malzemelerine yenilerinin de eklenmesini içerir. ${ }^{9}$ Aslında bu kanunun temeli, daha Cumhuriyet'in ilanında önce, hiçbir ülkenin egemenliği altına girmeksizin, kendi yerli kaynakları ile kalkınmanın sağlanması amacıyla Misak-ı İktisadi'nin kabul edildiği, 1923 yılında İzmir'de gerçekleştirilen Türkiye İktisat Kongresi ile atılmıştr. ${ }^{10} \mathrm{Bu}$ kongrede alınan kararlar, 1930'lara kadar dönemin iktisat politikalarını önemli ölçüde biçimlendireceği gibi, aynı zamanda yapı malzemesi endüstrisinde de ortaya çıkacak olan özel girişimlerin piyasa dinamiklerini büyük ölçüde yönlendireceği ikinci evrenin de başlangıcı olacaktır.

Bu kanun, 1913 tarihli ve aynı adlı kanunun genişletilmiş bir versiyonudur (Yücel, 2014, s. 15).

8 Kanun, yeni kurulacak işletmelere belediye sınırları dışındaki arazilerin devlet tarafindan karşılıksız, belediye sınırları içerisindekilerin ise arazi bedelinin 10 yıl içerisinde geri ödenmesi koşuluyla verilmesi; tesislerin kurulması veya gelişmesi için gerekli her türlü inşaat malzemesi, hammadde, araç-gerecin nakliyelerinin yurtiçinden sağlanamadığı durumlarda gümrük vergisinden muaf tutulmaları; kuruluşları sırasında yurtdışından getirilecek olan gereksinimlerin nakliyesinde \%30 indirim yapılması; haberleşme ve enerji ihtiyaçlarının devlet tarafindan sağlanması, vb. gibi hükümleri kapsar (Avcıoğlu, 1996, s. 381382).

Avcıoğlu, 1996, s. 381-382; Aslanoğlu, 2010, s. 92.

17 Şubat-4 Mart 1923 tarihleri arasında gerçekleştirilen bu kongrede, sanayicinin teşvik edileceği, ulaşım sektörünün geliştirileceği, ithal edilecek mallara gümrük muafiyeti sağlanacağı, kredi imkanlarının arttırılacağı, ipotek karşılığında tüccara kredi verileceği, ana ticaret bankasının kurulacağı ve tekelciliğin kabul edilmeyeceği bir "milli iktisat" politikası benimsenir (Yücel, 2014, s. 9-10). 
Bu yıllarda, endüstrinin geliştirilmesi yolunda alınan kararlardan bir diğeri ise, yerli üretimin ve özel girişimlerin teşvik edilmesi amacıyla bankaların kurulmasıdır. Bu kapsamda, 1924'te yerli kuruluşlara kredi sağlamak amacıyla Iş Bankası, 1925'te özel girişimlere kredi sağlamak, OsmanIı döneminden kalan fabrikaları kurulacak yeni şirketler devralana kadar işletmek ve yeni fabrikalar kurmak üzere Sanayi ve Maadin Bankası, 1926'da ise inşaat girişimlerini desteklemek ve kredi sağlamak üzere Emlak ve Eytam Bankası kurulur. ${ }^{11}$

Bu kurumsal gelişmelerin sonucunda, 1926 yılında yapı malzemesi endüstrisine yönelik Cumhuriyet döneminin ilk özel girişimleri ortaya çıkar. Bu girişimlerin en önemlileri arasında, 1926 yılında, İstanbul'da Bakırköy Çimentoları T.A.Ş. tarafindan kurulan Kurt Çimento Fabrikası ve Ankara Belediyesi tarafindan kurulan ve daha sonra Ankara Çimentoları A.Ş.'ye devredilecek olan Ankara Çimento Fabrikası'yla birlikte, 1928 'de Konya'da Krom Manyezit Tuğla Fabrikası'nın, 1929 'da Anadolu Çimentoları T.A.Ş.'nin girişimi olarak Kartal'da Yunus Çimento Fabrikası'nın ve 1930 yılında Türk Çimentosu ve Kireci A.Ş.'nin girişimi olarak Zeytinburnu Çimento Fabrikası'nın kurulması gösterilebilir. Çimentonun yanı sıra, betonarme inşaatlar için en temel malzemelerden biri olan demir üretimi için de bazı girişimlerde bulunulmuş ve yine 1926 yılında İstanbul'da ilk haddehane kurulmuştur. ${ }^{12}$ Ancak tüm bu fabrikalar, oldukça ilkel teknolojilerle üretim yapan, düşük kapasiteli ve "sonradan işe yaramayacak olan ilkel tesislerdir" ve yeterince işletilemedikleri gibi intiyacı karşılamakta da yetersiz kalırlar. ${ }^{13}$

Diğer taraftan, bu yıllarda, ulaşım ağlarının yeterli düzeyde olmaması nedeniyle, Anadolu'nun iç bölgelerinde üretilen yapı malzemelerinin kıyı bölgelerine, ithal edilerek kıyı bölgelerine gelen malzemelerin de iç bölgelere ulaştrıımasında sıkıntılar yaşanmaktadır. ${ }^{14}$ Yüksek nakliye masrafları nedeniyle, yapı malzemelerinin fiyatlarının artmasına neden olan bu durum, 1924'te demiryolu yapımı ve işletmeciliğinin devlet eliyle yapılmasını amaçlayan kanunla çözülmek istenir. ${ }^{15}$ Demiryolu ağlarının inşasının, yapı malzemelerinin nakliyesi ile ilgili problemleri ortadan kaldırılacağı öngörülmüşse de, ne yazık ki inşa edilebilen demiryolu miktarı çözüm olmamıştı. ${ }^{16}$ Yine de, erken Cumhuriyet yıllarında yapı üretimi endüstrisinin geliştirilmesi yolunda atılan ilk adımlar olmaları nedeniyle, yalnızca İstanbul'da da olsa, yapı malzeme fabrikalarının kurulma-

${ }^{11}$ Aslanoğlu, 2010, s. 18; Yücel, 2014, s. 12.

12 Sey, 1998, s. 27.

${ }^{13}$ Avcıoğlu, 1996, s. 394.

${ }^{14}$ Aslanoğlu, 2010, s. 93.

15 Yücel, 2014, s. 13.

161924 yılında mevcut 4000 km'nin üzerindeki demiryollarının 2350 km.si yabancı şirketler tarafindan işletilmektedir; 1931 yılına kadar $1630 \mathrm{~km}$ demiryolu inşa edilmiş ve 1929 km demiryolu yabancı şirketlerden satın alınmıştır. Aynı dönemde, karayolu yapımına yatırım yapılmışsa da, bu konuda önemli bir gelişme kaydedilmemiştir (Yücel, 2014, s. 13). sına ve ülke genelinde inşai faaliyetler için malzeme nakliyelerinin kolaylaştrılmasına yönelik bu girişimlerin önemi yadsınamaz.

Yerli üretimi geliştirmeye dayalı tüm bu çabalara ve girişimlere rağmen, Lozan Antlaşması'na göre önceden verilen gümrük muafiyetlerinin 1929 yılına kadar devam ettirilmesi ve Teşvik-i Sanayi Kanunu'yla ithalattaki gümrük vergilerinin kaldırılması, ithalat yapan ve yerli üretim yapan tüccarlar arasında rekabet edilemez bir ortam yaratr. ${ }^{17}$ Yeterli miktarda üretilemeyen yapı malzemelerinin ithal edilmesi, ayrıca bu malzemelerin fiyatlarının Anadolu'daki kentlere nakliye masrafları nedeniyle daha da artmasına bağlı olarak; çimento, Cumhuriyet'in ilk yıllarında, en pahalı yapı malzemelerinden biri haline gelir. Dönemin mimarlık yayınlarında "Avrupa'dan ithal edilen lüks malzeme" olarak tanımlanan çimentonun -betonarme sistemdeki bir binanın maliyetini arttırması nedeniyle- özel inşaatlarda kullanımından kaçınılmaya başlanır; çimento yalnızca büyük şehirlerde ve devlet eliyle yürütülen inşaatlarda kullanılan bir malzeme olur. ${ }^{18}$ Bu nedenle, erken evredeki yapı üretimini, dönemin ekonomik ve sanayi koşullarının belirlediği yapım tekniklerinin, yapı malzemelerinin ve donatılarının kullanıldığı görece büyük ölçekli kâgir yapılar tanımlar ve tüm çabalara rağmen gerçekleştirilen imar faaliyetleri oldukça kısıtı kalır. ${ }^{19}$

İnşaat sanayinin ve yapı malzemesi endüstrisinin gelişmemiş olmasının yanı sıra; dönemin mimarlık etkinliklerini kısıtlayan bir diğer önemli etmen ise, mimar ve mühendis düzeyinde teknik eleman, kalifiye işçi ve usta eksikliğidir. Önceki yıllarda yapı üretim sektöründe çalışan ustaların ve mimarların çoğunun gayrimüslim olması ve bunların savaş sonrasında ülkeden ayrılmaları nedeniyle, inşaatları gerçekleştirecek yeterli sayıda teknik eleman bulunmamaktadır. ${ }^{20}$ Teknik eleman eksikliğine getirilmeye çalışılan çözüm önerilerinden biri, kapsamlı bir imar faaliyetinin gerçekleştirildiği yeni kurulmakta olan başkent Ankara'da, 1929 yılında Ankara Sanat Okulu'nun bir dalı olarak Yapı Usta Okulu'nun ${ }^{21}$ açılmasıdır. ${ }^{22}$

Yapı üretiminde rol alan aktörlere yönelik bu sorun, yalnızca ustalar ile sınırlı değildir. Yaklaşık 1940'ların ortalarına kadar ülkede tek mimarlık okulunun var olması ${ }^{23}$ ve mimarlık eğitiminin Cumhuriyet yıllarına kadar, daha çok

\footnotetext{
17 Yücel, 2015, s. 29.

18 Selah, 1934, s. 155.

${ }^{19}$ Batur, 1998, s. 211-212.

${ }^{20}$ Batur, 1998, s. 210.

${ }^{21}$ Bozdoğan, ilkokul mezunlarının kabul edildiği ve "duvarcılık, marangozluk, sıvacılık ve taş kesiciliği" bölümlerinde 4 yıllık bir ustalık eğitiminin verildiği, Ankara Amele Mektebi'nin kuruluş tarihi olarak 1932 yılını belirtmektedir (Bozdoğan, 2002, s. 209)

${ }^{22}$ Aslanoğlu, 2010, s. 94.
}

${ }^{23}$ Mekteb-i Sanayi-i Nefise-i Şahane
adıyla 1883 yılında eğitime baş-
layan ve ismi 1928 yılında Devlet
Güzel Sanatlar Akademisi olarak
değiştirilen ilk mimarlık okulu (Mi-
mar Sinan Güzel Sanatlar Üniversi-
tesi), 1943 yılında -bugünkü adıy-
la- Yıldız Teknik Üniversitesi'nin ve
1944 yılında -bugünkü adıyla-İs-
tanbul Teknik Üniversitesi Mimar-
lık Fakültesi'nin kuruluşuna kadar,
mimarlık eğitimi veren tek okuldur
(Özgüven, 2002, cilt 1, s. 13-20). 
gayrimüslimler tarafindan tercih edilmesi, beraberinde oldukça az sayıda Türk mimarın mezun olmasını getirmiştir. Dolayısıyla, erken Cumhuriyet yıllarına kadar mimarlık ve yapı üretim sektörünün, gerek eğitim, gerek tasarım, gerekse de uygulama alanlarının büyük oranda gayrimüslimlerin rağbet ettikleri bir alan olduğu söylenebilir. Ancak 1927-28 yılları, bu mimarlık ortamının değişiminde bir dönüm noktasına işaret edecektir. 1927 yılında Ankara'da Türk Mimarlar Cemiyeti'nin, ${ }^{24} 1928$ yılında İstanbul'da Güzel Sanatlar Birliği'nin kurulması, ${ }^{25}$ Jansen'in 1927 yılında Ankara'nın imar planı için açılan uluslararası yarışmayı kazanması ile yabancı mimarların ülkedeki etkin varlığının da ilk adımını oluşturması, ${ }^{26} 1931$ 'de Türkiye'nin ilk mimarlık süreli yayını olan Arkitekt'in yayınlanmaya başlaması, ülkedeki mimarlık ortamı açısından önemli gelişmelerdir. Gerek yabancı mimarların uygulamaları, gerekse de yeni mezun genç Türk mimarlarının bir araya gelerek, yeni mimar kimliğini oluşturma çabaları ve dönemin ideolojisine uygun olarak modern mimariyi uygulamaya yönelik girişimleri, ülkedeki mimarlık ortamının sonraki on yılındaki yönelimini belirleyecektir.

\section{İkinci Evre: Devletçilik Politikaları Kapsamında Yapı Malzemesi Endüstrisi ve Mimarlık Ortamı}

Cumhuriyet'in ilanıyla birlikte kültürel, politik, ekonomik ve toplumsal olmak üzere tüm alanlarda benimsenen "çağdaş uygarlık düzeyine erişme" idealinin, ülke genelindeki modernist uygulamalarla fiziksel görünürlük kazandığı bu dönemi belirleyen, planlı devletçi politikalar olmuştur. 1929 'da ortaya çıkan Dünya Ekonomik Bunalımı'nın etkilerinin en az düzeye indirilmesini amaçlayan ve savaş yıllarına kadar uygulanacak olan korumacı ve içe dönük bu politikalar, dönemin mimarlık ortamının yönelimleri ile Cumhuriyetçi ideolojinin örtüşmesine bağlı olarak, aynı zamanda yapı üretim etkinliğinde de önemli gelişmeleri beraberinde getirmiştir. ${ }^{27}$ "Modern" ve "asri" bir Cumhuriyet mimarlığının yaratılması amacıyla dönemin mimarlarının tutkuyla katıldıkları bir program haline gelen bu ideal çerçevesinde, ${ }^{28} 1930$ 'lar, mimarlık ortamında önemli kırılmalara ve değişimlere sahne olarak, Türkiye'nin "mimarlık ve yapı üretimi serüveni" adına simgesel bir başlangıç noktası tanımlar.

Modern Türkiye'nin de inşa süreci olarak tanımlanabilecek olan bu dönemde, yeni başkent Ankara'da diğer

\footnotetext{
24 Türk Mimarlar Birliği, dernek sta- ${ }^{25}$ Bu kurumlar, Türkiye'de kurulan mitüsüyle kurulmuş olmakla birlikte; "daha çok uygulamaların düzenlenmesi, ihale alımı ve mimarların mesleki, iktisadi ve hukuki çıkarlarının korunması" (Bozdoğan 2002 s. 177) ile ilgilenecek; yasal örgütlenme ve bilgi alışverişini sağlama yolunda etkili bir çalışma programı başlatacaktır (Batur, 1998, s. 220; Sey, 1998, s. 32)

mari anlamda ilk profesyonel mes mari anlamda ilk profesyonel mes-
lek örgütleridir. 1935 yılında her ik kurum birleşerek, İzmir'de bir şube açacak ve 1950 yılında kurulacak olan Mimarlar Odası'nın ilk nüvelerini oluşturacaklardır (Bozdoğan, 2002, s. 177).

Batur, 1998, s. 220

27 Batur, 1998, s. 214.

${ }^{28}$ Batur, 1998, s. 213.
}

kentlere örnek oluşturacak olan "Cumhuriyet'in mimari kültürünün kurulması" amacıyla, yoğun biçimde yapım etkinliklerine başlanır. Yüzyıllardır süregelen mimari üretim biçimlerinin ve mimari geleneğin izlerini taşımayan, tıpkı Batı'daki başkentler gibi modern ve düzenli bir kent yaratılması amacıyla, özellikle Almanya ve Avusturya gibi yakın ilişkilerin olduğu ülkelerden çok sayıda mimar, şehir plancısı ve heykelttraş davet edilir. Bu mimarlar, başta C. Holzmeister olmak üzere öncelikli olarak modernliğin simgesi olacak olan çeşitli kamu binalarının yapımında görevlendirilirler. Anıtsal ölçekli modern çizgilerdeki Milli Savunma Bakanlığı, Genelkurmay Başkanlığı, İçişleri Bakanlığı, Bayındırlık Bakanlığı, Ekonomi ve Ticaret Bakanlığı, Merkez Bankası, Yargıtay ve TBMM binası gibi kamu yapıları, aynı zamanda Holzmeister’ı dönemin en güçlü ve etkin mimarı haline getirir. Betonarme karkas sistemdeki ve yalın bir mimari dile sahip olan bu bakanlık binalarının yanı sıra, M. Elsaesser, M. Wagner, E. Egli, C. Holzmeister, T. Jost gibi yabancı mimarların özellikle Ankara'da kamuya ait Sümerbank ve Cebeci Mezarlığı, Atatürk Orman Çiftliği Kompleksi, Devlet Konservatuarı, Siyasal Bilgiler Fakültesi, Ziraat Fakültesi, Türk Hava Kurumu, Ankara Kız Lisesi, Hıfzıssıhha Enstitüsü gibi büyük ölçekli yapılarında, S. Arkan, Ş. Balmumcu, Z. Sayar, A. Mortaş ve A. Z. Kozanoğlu gibi genç Türk mimarların ise Sergi Evi ve Ankara Garı gibi görece büyük ölçekli betonarme yapılar dışında, daha çok konut yapılarında ve/veya küçük ölçekli yapılarda görünürlük kazanır (Şekil 2, 3). Hatta, modernist eğilimleri ile ön plana çıkan ve "Atatürk'ün mimarı" olarak ün kazanan Seyfi Arkan'ın bile, en bilinen mimari etkinliklerinin, dönemin yabancı mimarlarına göre görece daha küçük ölçekli Hariciye Köşkü, Camlı Köşk ve Florya Köşkü gibi yapılar olması dikkat çekicidir.

Bu bağlamda, yapı etkinliklerinin de büyük ölçüde Ankara'daki devlet ve kamu yapılarıyla tanımlandığı bu yıllarda, bir yandan da hızlı sanayileşmeye odaklanılır ve dönemin çerçevesini devletin ekonomik olarak daha etkin ve güçlü bir rol oynamasına, sanayi alanında yapılacak tüm girişimlerin ve sürecin belirli bir plan kapsamında yürütülmesine dayanan devletçilik ilkesi ${ }^{29}$ oluşturur. Bu doğrultuda, devletçilik ilkesinin de benimsendiği 1932 yılında hazırlanmaya başlanan ve 17 Nisan 1934'te yürürlüğe konulacak olan Birinci Beş Yıllık Sanayi Planı, ${ }^{30}$ yapı malzemesi endüstrisinin gelişimi için de belirleyici olacaktır. Aslında, yapı malzemesi endüstrisinin gelişimi; altyapı yatırımları, sağlık ve eğitim harcamaları, tarım ve hizmet sektörlerini dışarıda bırakarak, tamamen sanayi sektörüne odaklanan ve bir plandan öte, daha çok devletin sanayi yatırımlarına ilişkin bir liste olarak tanımlanabilecek olan bu planın ${ }^{31}$ odak noktasında yer almaz. Ancak, 1933'te bu planın uygula-

\footnotetext{
${ }^{29}$ Yücel, 2014, s. 23.

${ }^{30}$ Yücel, 2014, s. 22, 26.

${ }^{31}$ Yücel, 2014, s. 26-17; Avcıoğlu, 1996 , s. 451.
} 

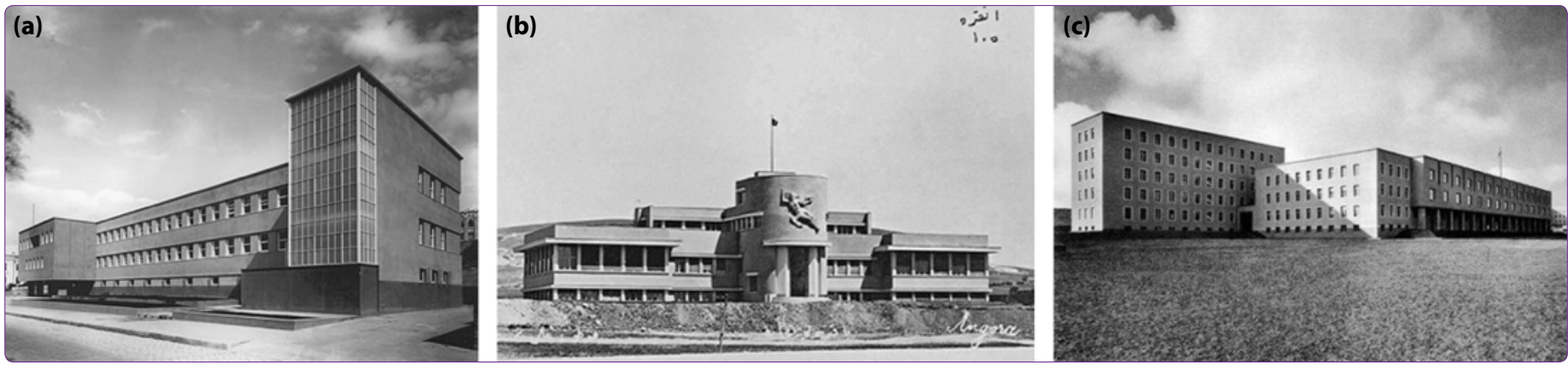

Şekil 2. (a) Türk Hava Kurumu, E. Egli, 1937 (Alpagut, 2015); (b) Hıfzıssıhha Enstitüsü, T. Jost, 1932 (Yılmaz \& Çügen, 2011); (c) İç İşleri Bakanlığı, C. Holzmeister, 1934, (www.arkitera.com).
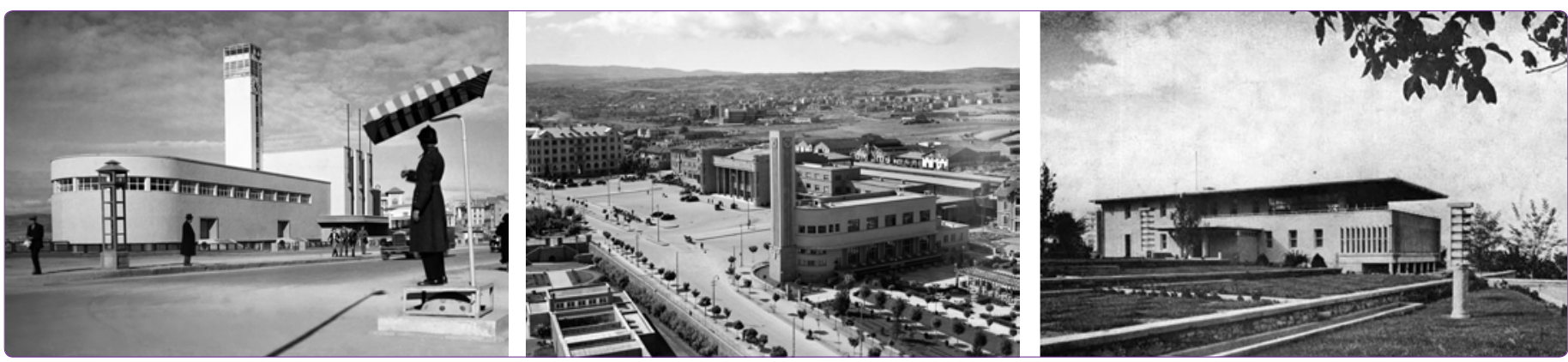

Şekil 3. (a) Ankara Sergi Evi, Ş. Balmumcu, 1934 (commons.wikimedia.org); (b) Ankara Gar Binası, Ş. Akalın, 1937 (Anonim); (c) Hariciye Köşkü, S. Arkan; 1934 (Arkitekt, 1935, sayı 11-12).

masını yürütecek olan Sümerbank'ın, ${ }^{32} 1935$ 'te Etibank'ın ve Maden Tetkik Arama Enstitüsü'nün kurulması, 1939'da Sümerbank'a bağlı en büyük teşebbüs olan Karabük DemirÇelik İşletmeleri'nin faaliyete geçmesi ve 8 Şubat 1937 'de Orman Umum Müdürlüğü tarafindan 3116 sayılı Orman Yasası'nın çıkarılması gibi girişimler, dönemin yapı üretimini ve yapı malzemeleri endüstrisini doğrudan etkiyecek olan önemli gelişmelerdir. ${ }^{33}$ Bu gelişmelerin, dönemin mimarlık ortamında yol açt̆ğı en önemli etkinlik, yeni üretim pratiklerinin belirlediği fabrika binalarının ve fabrika merkezli bu yeni yaşam pratiklerinin belirlediği işçi konutlarının ortaya çıkışıdır. Bu kapsamda, Karabük-Demir Çelik Fabrikası ve yerleşkesinin yanı sıra, Sümerbank tarafindan inşa edilen Kayseri Pamuklu Bez Fabrikası, Nazilli Basma Fabrikası ve Merinos Yünlü Dokuma Fabrikası gibi büyük ölçekli fabrikalar ve iş̧̧i konutları/lojmanlarını da içeren büyük ölçekli fabrika yerleşimleri, kentsel ve mekânsal biçimlenişleriyle Cumhuriyet Türkiyesi'nde yeni bir yapı tipolojisi oluşturarak, mimarlık gündemini belirlemişlerdir (Şekil 4). Özellikle

\footnotetext{
32 1934-1937 yılları arasında, farklı şehirlerde 15 kadar fabrika inşa edecek olan (Bozdoğan, 2002, s. 141), Sümerbank'ın sorumlulukları arasında Devlet Sanayi Ofisi'nden devralacağı fabrikaları yönetmek, devlet sermayesi ile kurulacak tüm sanayi tesislerinin projelerini hazırlamak ve yönetmek, ülkeye faydalı olacak çeşitli sanayi tesislerini kurmak ve genişletilmesine yardım etmek, usta ve işçileri yetiştirmek

üzere okullar açmak, sanayi alanında çalışacak uzman ve mühendisleri yetiştirmek üzere öğrenciler okutmak, eğitim amacıyla yurtdışına öğrenci ve stajyerler göndermek, sanayi kuruluşlarına kredi sağlamak, milli sanayinin gelişmesini sağlamak yer almaktadır (Yücel, 2014, s. 25).

${ }^{3}$ Aslanoğlu, 2010, s. 48, 95; Yücel, 2014, s. 30.
}

Seyfi Arkan'ın Zonguldak'taki maden iş̧̧ileri için tasarladığı Türk-Iş ve Kömür-isş işçi yerleşkeleri, modernist eğilimleri ile dönemin Türk mimarlarının etkinliklerinde önemli bir yere sahiptir (Şekil 5).

Diğer taraftan, tüm bu kararlar ve uygulamalar doğrultusunda, tüm sanayi alanlarında olduğu gibi, ithalatın durdurularak, yapı malzemelerinin üretiminin devlet eliyle yürütülmesi çabalarına rağmen; kuruluş yıllarının tanımladığı erken evrede, yerli üretimin sağlanması için teşvik edilen özel girişimler, aralarında kuracakları satış birlikleri aracılığıyla sektörde daha etkin bir rol üstleneceklerdir. 2. Dünya Savaşı yıllarına kadar artarak devam edecek olan bu satış birliklerinin neredeyse tüm sanayi alanlarında varlık kazanması, 1930'lar boyunca, zaten sıkıntlı olan yapı üretim etkinliğinde yaşanan problemleri daha da arttracak; ticaret piyasasının dinamikleri de yapı üretim etkinliğinde başat bir rol üstlenerek mimarlık gündemini belirleyecektir.

Bu dönemde, "doğası gereği, görsel modernlik kültürünün merkezi unsurlarından biri olarak öne çıkan mimari"34 betonarme yapım teknikleri ile özdeşleştirilmiştir. Dolayısıyla, başta başkent Ankara olmak üzere, yoğun biçimde yürütülen tekil yapılardan, rıhtımlara, yollara ve köprülere kadar her ölçekteki yapı üretimi, çimento gibi tamamen betonarme yapım sisteminin ihtiyaç duyduğu yapı malzemelerine dayalıdır ${ }^{35}$ (Şekil 6).

\footnotetext{
34 Bozdoğan, 2002, s. 74
} 



Şekil 4. (a) Kayseri Pamuklu Bez Fabrikası ve Yerleşkesi, 1935, (Anonim); (b) Merinos Yünlü Dokuma Fabrikası, 1938 (Anonim); (c) Ereğli Bez Fabrikası İşçi Konutları, 1944 (Arkitekt, 1944, sayı 1-2).
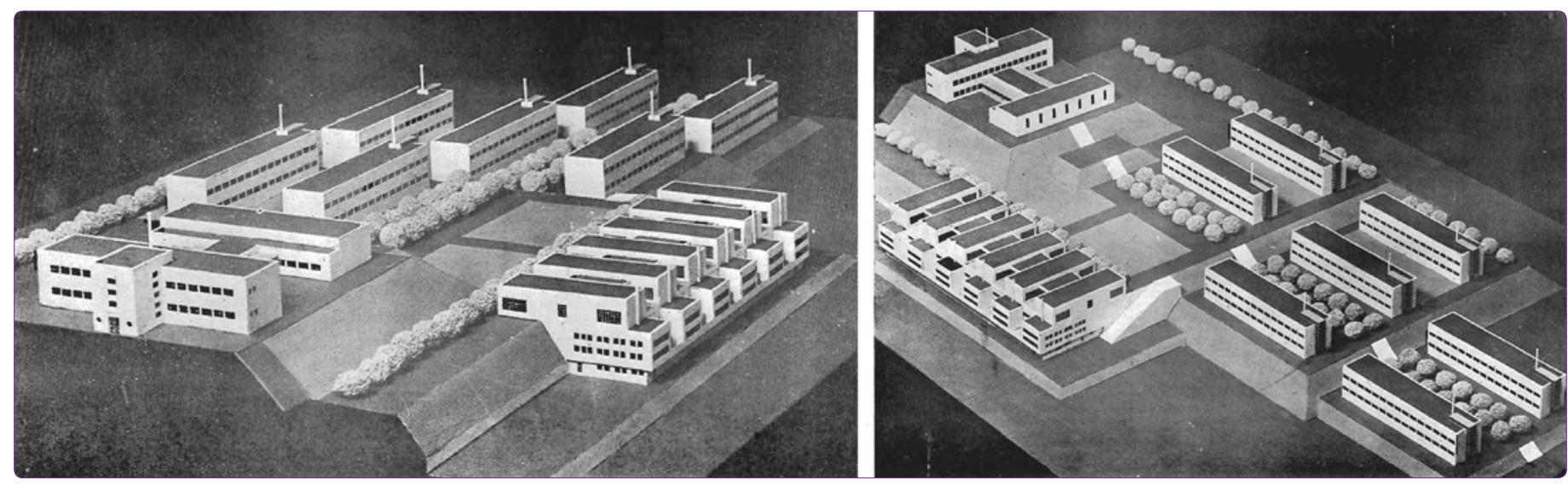

Şekil 5. Zonguldak Türk-iş İşçi Konutları, yatakhaneler ve servis yapısı, 1935 (Arkitekt, 1935, sayı 9).

Betonarme yapıların, şehirlerden köylere kadar ülkenin her yerinde yaygınlaşmasıyla, kentlerin çağdaş ve modern bir mimariye sahip olabileceği düşüncesi bu yıllarda o kadar etkilidir ki, dönemin yayınlarında "Bugün, beton inşaat devridir" şeklinde ifade bulur. ${ }^{36}$ Ancak, Dünya Eko-

\footnotetext{
${ }^{35}$ Anonim, 1936a, s.243. Konu ile ilgili olarak Başbakanlık Cumhuriyet Arşivi'nde yer alan bazı belgeler için bkz. "Sivas-Malatya-Elazız-Diyarbekir yolundaki Fırat nehri üzerinde betonarme köprü inşaası" (BCA, 30-18-1-2/9 -11-5, 12.03.1930), "Yapılacak olan 11 adet betonarme köprünün kambiyo alımı" (BCA, 30-18-
}

nomik Bunalımı́nın etkisiyle ithalatın durdurulduğu ve devletçi sanayi politikaları kapsamında yeni fabrikaların kurulmasının da Sümerbank aracılığıyla devlete bırakıldığı bu dönemde, ülkedeki mevcut yapı malzemesi endüstrisi, inşaat sektörü, teknolojik ve teknik altyapı, modern mimari uygulamalarının gereksinimlerini sağlamakta yetersiz olduğu gibi, gerçekleştirilen imar faaliyetleri de bu yeni malzemelerine yönelik talebi sürekli arttrmaktadır. Bu dönemde, "milli" üretimin sağlanması ve hammaddelerin değerlendirmesi amacıyla, devletin temel intiyaçlarına yönelik tesislerin coğrafi özellikler göz önüne alınarak 



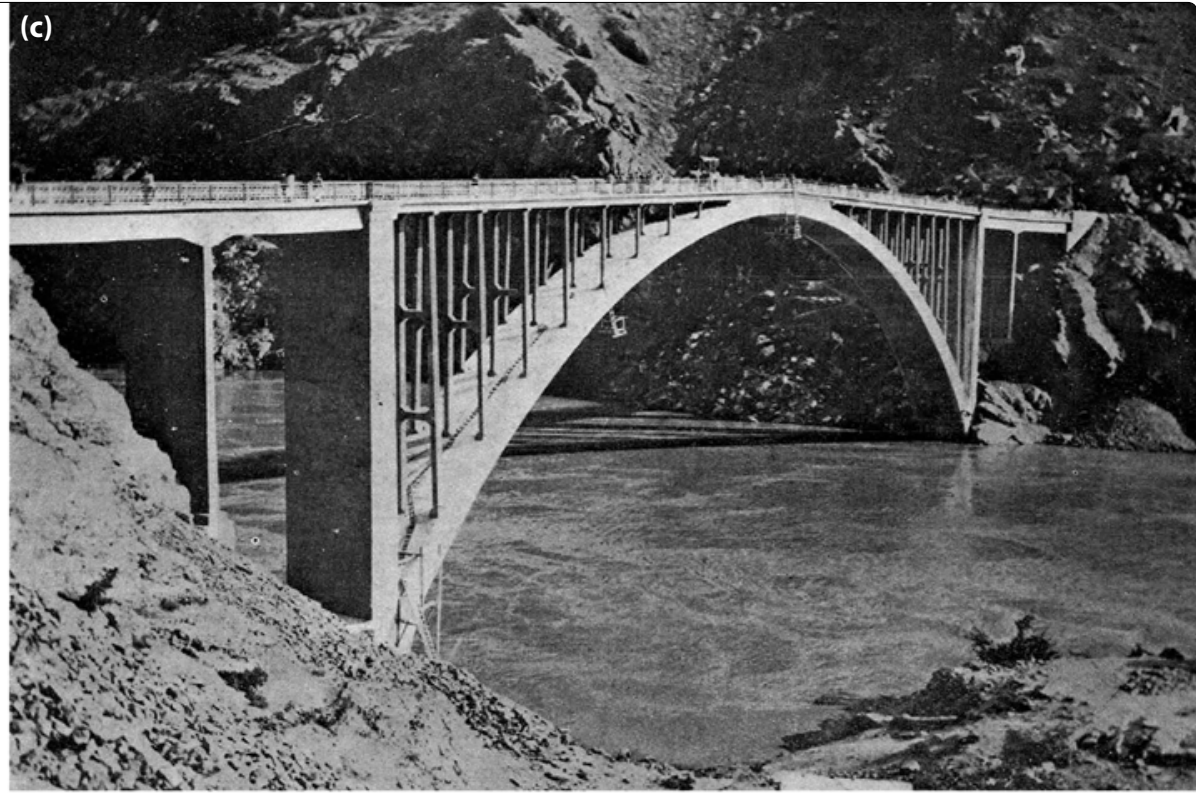

(d)

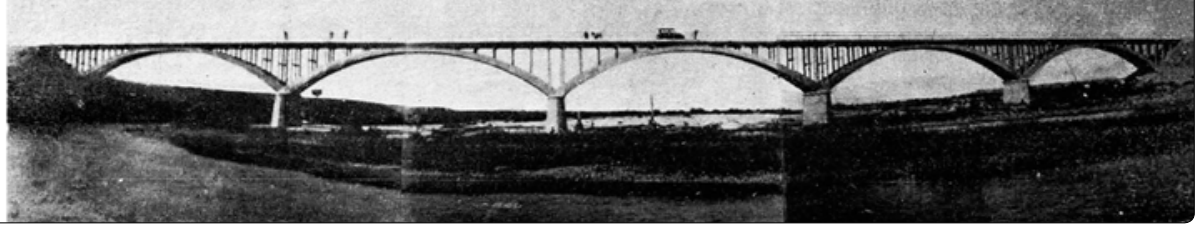

Şekil 6. (a) Atatürk Orman Çiftliği Bira Fabrikası, E. Egli, 1937 (Alpagut, 2015); (b) İsmet Paşa Kız Enstitüsü, E. Egli, 1934 (Anonim); (c) İsmet Paşa Köprüsü (Arkitekt, 1933, sayı 9-10); (d) Akçay Köprüsü (Arkitekt, 1933, sayı 9-10).

kurulması kararlaştırılmış ${ }^{37}$ ve bu çerçevede, henüz yeni faaliyete geçmiş olmasına rağmen, Sümerbank tarafindan 1934 yılında Kütahya'da bir seramik fabrikasının kurulması gündeme gelmiştir. ${ }^{38}$ Benzer biçimde, yine Birinci Beş Yıllık Kalkınma Planı kapsamında, devlet eliyle sanayi tesislerinin kurulması yolunda kararlar alınmışsa da; 1937 yılında temelleri atılan Karabük Demir-Çelik Fabrikası ancak 1939 'da, ${ }^{39}$ beş yıl içerisinde faaliyete geçmesi planlanan Sivas Çimento Fabrikası ise 1943 yılında faaliyete geçebilmiştir. ${ }^{40}$

Fabrikaların açılarak, yapı malzemelerinin devlet eliyle üretilmesi, mimarlık çevreleri tarafindan da destek bulur ve yapı malzemelerinin üretimini kolaylaştırmak adına, dönemin mimarlık yayınlarında teşvik edici öneriler yayınlanır. Sümerbank tarafindan, 1934 yılında, henüz kurulmakta olan yan kok fabrikasının işleyeceği kömürden üretilecek katran ile, betonarme inşaatlar için gerekli olan yalıtım malzemelerinin, iş Bankası tarafindan kurulmakta olan şişe fabrikası Paşabahçe Fabrikası'nda ise ${ }^{41}$ modern mimarinin ana unsurlarından biri olan kalın tavan camlarının üretilmesinin mümkün olduğu ifade edilir. ${ }^{42}$ Ancak, yapı malzemeleri endüstrisi de dahil olmak üzere, devletin tüm sanayi

\footnotetext{
37 Doğan, 2013, s. 216-217.

${ }^{38}$ Anonim, 1934a, s.190.

${ }^{39}$ Anonim, 1937b, s. 62.
}

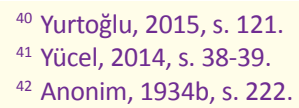

sektörünü yeniden şekillendirecek olan bir "milli" sanayinin oluşturulması yolundaki bu kararları, özel girişimler arasında hoşnutsuzluk yaratacak; bunun üzerine, farklı alanlarda faaliyet göstermekte olan yapı malzemesi fabrikaları, 1932 yılından itibaren çeşitli satıs birlikleri kurmaya başlayacaktır. Bu satış birliklerinin, fiyatları ve üretim miktarlarını tespit ederek piyasa dinamiklerini yönlendirmeleri sonucunda, yapı malzemeleri fiyatları, 1930'ların ortalarından itibaren o güne kadar görülmemiş bir oranda artacaktır.

Yapı malzemesi sektörü bağlamında, dönemin yapı üretimini en fazla etkileyecek olan çimento fabrikalarının aralarında meydana getirdikleri satış birliğidir. 16 Kasım 1931 tarihinde 11.940 sayılı kararname ile önce ithalatının sınırlandırılması, sonra da tamamen durdurulması, ${ }^{43}$ Türkiye'de yerli üretim yapan çimento fabrikalarının aralarında bir satış birliği kurmalarıyla sonuçlanır. Erken evrede sanayinin teşvik edilmesi yolundaki kararlarla kurulmuş olan bu fabrikalar, henüz devlet eliyle kurulmuş bir çimento fabrikası olmamasından faydalanarak, üretim ve satı̧̧ piyasasını paylaşarak, çimento fiyatlarını yükseltirler. ${ }^{44}$ Ancak bu dönemde, İktisat Vekâleti ve Sümerbank tarafindan sürdürülmekte olan çok sayıdaki yeni fabrikanın ve demiryollarının inşasının yanı sıra, özel inşaatların sayısındaki artı̧̧a

\footnotetext{
${ }^{43}$ Dölen \& Koraltürk, 2004, s. $85 . \quad{ }^{44}$ Selah, 1934, s. 155
} 
bağlantılı olarak çimento ihtiyacı yapı üretimi için o kadar belirleyicidir ki; dönemin yayınlarında, imar faaliyetlerinin yürütülmesinin çimentonun ucuzluğu oranında mümkün olabileceği, "imar siyaseti, çimento siyasetidir" 45 biçiminde açıklanır. Yerli çimento üreticilerinin oluşturdukları bu "tröst"ün yapı malzemeleri endüstrisindeki yetkinliği, doğu illerinden birinde bir çimento fabrikasının kurulacağının gündeme gelmesi üzerine, çimento fabrikasının inşa edilmemesi karşılığında, fabrikaların fiyatlarda indirim yapmayı kabul etmesi ile de görünürlük kazanır. ${ }^{46}$

Bu durum, 1935-1938 yılları arasında devletin çimento endüstrisine müdahalesini de beraberinde getirir. Devlet, 1935 yılından itibaren çimento fiyatlarına müdahale etmeye başlar, ${ }^{47}$ ancak fiyatlara yapılan müdahale sonuç vermeyince, 1936 yılında çimento ithalatına izin vermek zorunda kalı. ${ }^{48}$ Diğer taraftan, vergilerin hafifletilmesiyle çimento fiyatlarında \%50 civarında bir indirim sağlansa da, ${ }^{49}$ çimento teminindeki sıkıntılar devam etmektedir. ${ }^{50}$ Hükümetin çimento sektörüne yönelik müdahaleleri, 1937 yılında çimentonun niteliği, üretimi ve dağıtımını kontrol etmek üzere hazırlanan kararnameler ${ }^{51}$ ile devam eder. ${ }^{52}$ Ancak, bu uygulamalar, belirlenen çimento standartlarının gerektirdiği teknolojik yatırımları yapamayan Ankara ve Bakırköy fabrikalarının faaliyetlerini durdurmak zorunda kalmalarıyla sonuçlanarak; ;3 zaten ihtiyacı karşılamakta yetersiz kalan çimento üretiminin daha da azalmasına neden olur. Dolayısıyla, devletin tüm bu önleme çabalarına rağmen, bu yıllarda, mimari etkinliğini belirleyen çimento fiyatları, sürekli biçimde artmaya devam eder.

Devletin kereste sanayini doğrudan etkileyecek olan çeşitli müdahaleleri, kereste üretiminde de özel girişimlerin bir tekel oluşturmasına yol açar. Devletçilik uygulamaları kapsamında, 25.10.1935 tarih ve 70 sayılı gerekçe sunulan ve 1937 yılında yürürlüğe giren Orman Yasası'yla birlikte,, ${ }^{54}$ tüm ormanlar devletleştirilerek, odun üretimi tamamen devlete bırakılır. ${ }^{55}$ Fabrikaların yalnızca devlet tarafindan

\footnotetext{
${ }^{45}$ Selah, 1934, s. 155.

${ }^{46}$ Anonim, 1934b, s. 222.

47 Avcıoğlu, 1996, s. 395.

48 ilk kez 1936 yılında, 40.000 ton çimentonun ithal edilmesine izin verilir (Anonim, 1936b, s. 273).

49 "Son aylarda baş gösteren çimento buhranını önlemek için yabancı memleketlerden ithal edilecek 40 bin ton çimentoya münhasır olmak üzere gümrük tarifesinin (469 A) numarasına giren çimentoya mevzu gümrük resminin yüz kiloda 30 kuruşa indirilmesine Vekiller $\mathrm{He}$ yetince karar verilmiştir" (Anonim, 1937c, s. 313).

${ }^{50}$ Avcıoğlu, 1996, s. 395.

${ }^{51}$ Çimentonun üretimi ve niteliğini belirlemek amacıyla, 9 Ocak 1937 tarihinde "Türk Portland Çimento ve Yüksek Fırın Portland Çimento Normlarına Dair Kararname" ve Ağustos

1938'de de "Türk Çimento Normları Hakkında Nizamname" çıkarılır (Dölen \& Koraltürk, 2004, s. 87).

52 Anonim, 1937a, s. 30.

${ }^{53}$ Dölen \& Koraltürk, 2004, s. 87.

${ }^{54}$ Birben, 2008, s. 4.

${ }^{5} \mathrm{Bu}$ yasa ile, odun üretiminin, ormanların özel girişimlere ihale edilmesi yoluyla gerçekleştirilmesine son verilir ve on yıl içerisinde tüm özel girişimlerin orman işletme belgelerinin alınarak, devlet orman işletmeciliğine geçilmesi kabul edilir (Gümüş, 2014, s. 481-482). Yasa köylülerin devlet ormanlarından serbestçe yararlanmasını ortadan kaldırmakla birlikte, belirli büyüklükteki ormanların, iki yıl içerisinde bedelleri karşılığında istimlak edilerek devlet ormanı haline getirilmesini de içermektedir (Geray \& Ok 2001, s. 4)
}

verilecek tomrukları işleyebilecek olmaları, betonarme inşaatlarda kalıp olarak kullanılan yerli kerestelerin fiyatlarının artmasına neden olurken; Zingal dışındaki neredeyse tüm kereste fabrikaları, hammadde bulamadıkları için faaliyetlerini durdurmak zorunda kalır. ${ }^{56}$ Zingal ve bankaların elinde bulunan diğer fabrikaların aralarında bir satış birliği kurarak, fiyatları ortaklaşa belirlemeleri, kereste fiyatlarındaki artş̧ın devam etmesine ve aynı zamanda kereste ile üretilen diğer yapı malzemelerinin de fiyatlarının artmasına neden olur. ${ }^{57}$

Betonarme inşaatlarda kullanılan çimento ve kalıplık kereste fiyatlarındaki bu artş̧lar, kiremit ve çivi gibi diğer yapı malzemelerinde de etkili olmuş; fabrikaların aralarındaki rekabet ortamına son vererek anlaşmaları üzerine, tuğla, demir, cam, fayans ve elektrik gibi tesisat malzemeleri de dahil olmak üzere tüm yapı malzemelerinin fiyatlarında artş̧lar meydana gelmiştir. Özellikle, Ankara'da devam eden imar faaliyetleri ve betonarme inşaatlara bağlı olarak, çimentonun yanı sıra demir ihtiyacı da oldukça fazladır. Ancak, artan talep karşılanamadığı gibi, 1935 yılında demire tüketim vergisinin de getirilmesiyle, demir fiyatları daha da yükselmiştir. ${ }^{58} \mathrm{Bu}$ duruma, malzemelerin üretiminde belirli bir kalite ve boyut standardının bulunmaması ve inşaat yoğunluğuna bağlı olarak sürekli artan intiyaçlar da eklenince, düşük kalitede ancak pahalı ürünler kullanılmak zorunda kalınmıştır. Modern betonarme inşaat tekniklerinin ihtiyaç duyduğu çimento ve demir gibi temel yapı malzemelerinin üretiminde ve temininde yaşanan sıkıntıların yanı sıra; bu inşaatların gerektirdiği yalıtım malzemeleri, çimento karıştrıcılar, beton dökme ve karıştırma gibi inşaat aletleri ve makineleri, boru, karo, yer kaplamaları gibi ince yapı malzemeleri başta olmak üzere ülke sınırları içerisinde üretilemeyen çeşitli malzemelerin kullanımının ithalata bağımlı olması ve ülke içerisindeki nakliye masraflarının fazla olması, bu malzemelerin kamu inşaatları dışındaki diğer yapılarda kullanılmasını zorlaşmıştır. Dolayısıyla, bu yıllarda geniş ölçekli imar faaliyetleri ve yapı üretimini belirleyen, yapı malzemesi endüstrisinde devlet ve özel girişimler arasında karşııklı alınan kararlar ve ithalat olanakları olmuştur.

Yapı malzemesi sektörünü olduğu kadar, 1930'lu yılların mimari ortamını da belirleyen "devletçi ekonomi politikasına doğrudan bağımlı" bir yapı programı olmuştur. ${ }^{59} \mathrm{Bu}$ bağımlılık, hem dönemin yapı üretim etkinliğinin nerdeyse tamamını meydana getiren kamu yatrımlarına, hem de devletçilik ilkesi kapsamındaki sanayileşme uygulamalarının şekillendirdiği yapı malzemesi endüstrisine işaret eder. Bu yıllarda, çağdaşlaşma ve modernleşme idealiyle, başta Ankara olmak üzere, kentlere çağdaş bir görünüm kazandırılması amacıyla gerçekleştirilen yapı üretimi etkin-

\footnotetext{
${ }^{56}$ Anonim, 1935b, s. 358; 1936c, s. 273.

${ }^{57}$ Anonim, 1938, s. 276

${ }^{58}$ Anonim, 1935a, s. 155

${ }^{59}$ Batur, 1998, s. 217
} 
likleri, bir yandan da dönemin sanayileşme politikaları ile bağlantılı olarak fabrikaların inşasını da beraberinde getirir. Fabrikalar gibi, bu yıllarda gerçekleştirilen büyük bulvarlar ve meydanlar, kent parkları ve bahçeleri, belediye binaları, demiryolu istasyonları, halkevleri, ilkokullar, hastaneler ve sosyal konutların inşasında kullanılan betonarme sistem ve bu yapıların kentler için tanımladığı "yabancı" yapı tipolojisi, ${ }^{60}$ aynı zamanda dönemin yapı üreticileri olan mimarlar ve kültür ortamı için de "yabancı"laşma olarak adlandırılabilecek gelişmelere neden olur. 1930'ların modernleşme ideali ekseninde biçimlendirilen mimari kültür ortamı ve inkılâba özgü yeni mimarinin tanımladığı yapı üretimi etkinlikleri, ${ }^{61} 1928^{\prime}$ de, H. Jansen tarafindan Ankara İmar Planı'nın hazırlanması ile başlar ${ }^{62}$ ve 1928-1940 yılları arasında, ülkeye, başta Ankara'da inşa edilecek yapılar için olmak üzere, çok sayıda yabancı şehir planlamacısı ve mimar davet edilmesiyle devam eder. ${ }^{63}$

Yapı üretimindeki aktörler, yapı malzemeleri, yapı tipolojisi ve yapım teknikleri gibi mimari etkinliklerin gerçekleştirilmesinde önemli bir rol oynayan bu "yabancı" olma durumu, savaş yıllarıyla birlikte kesintiye uğrayacaksa da, savaşın sona ermesiyle her alanda olduğu gibi, mimarlık ortamında gündemi belirlemeye ve yapı malzemesi endüstrisini yönlendirmeye devam edecektir.

\section{Çözülme Evresi: 1939-1950 Yılları Arasında Yapı Malzemesi Endüstrisi ve Mimarlık Ortamı}

Devletçi politikalar kapsamında bir milli sanayinin kurulmasına yönelik gerçekleştirilen girişimlerle, yeni fabrikalar ve tesisler kurulmuş olmasına rağmen, 1930 'lar boyunca yürütülen imar faaliyetleri ve yapı üretiminin ihtiyaç duyduğu yapı malzemeleri, yerli üretimle karşılanamamış; 1937 yılından itibaren devletçilik ilkesinin çözülme içerisine girmesiyle ${ }^{64}$ tekrar ithalatla beslenmeye başlayan yapı malzemesi endüstrisi için 2. Dünya Savaşı, oldukça sıkıntılı bir süreci de beraberinde getirmiştir. Özellikle 1939-1943 yılları arasında, bir yandan savaş nedeniyle yapı malzemesi ithalatının neredeyse durmuş olması, diğer yandan ülkedeki mevcut fabrikaların ithalattaki sıkıntılara bağlı olarak yedek parça, kömür, vb. hammaddeleri temin edememesi nedeniyle, fabrikalar çok zor koşullarda ve aralıklı olarak üretimlerini sürdürebilmektedirler. ${ }^{65}$ Savaş yıllarının tanımladığı, 1940'ların ilk yarısı, aynı zamanda yapı üretimi

\footnotetext{
${ }^{60}$ Batur, 1998, s. 217; Sey, 1998, s. 31.

${ }^{61}$ Bozdoğan, 2002, s. 72-78.

roller üstleneceklerdir (Bozdoğan, 2002, s. 86)

62 Ernst Egli, Clemenz Holzmeister, Martin Wagner, Bruno Taut, Martin Elsaesser, Franz Wilhelm Lihotsky, Margarete Schütte-Lihotzky bu mimarlardan bazılarıdır. 1933 yılından sonra ise, 40' olmak üzere, 200'den fazla Alman, Avusturyalı ve İsviçreli eğitimci ve danışman Ankara ve İstanbul'daki üniversitelerdeki eğitimde önemli
}

ve mimarlık ortamında da büyük bir durgunluk döneminin başlangıcını oluşturur.

Ülke genelinde yapı üretiminin, yapı malzemelerinin temin edilememesi nedeniyle durağan bir seyir izlediği bu yıllar, aynı zamanda 1930'larda Ankara'nın başkent olarak imarı kapsamında gerçekleştirilen imar faaliyetlerinin, İstanbul'a odaklandığı yıllardır. Prost tarafindan İstanbul'da yapılması planlanan stadyum, kent parkları, geniş bulvarlar, meydanlar, köprüler, gazinolar, plaj ve deniz hamamları, gezinti yolları gibi geniş ölçekli kentsel müdahaleler ve nüfus artışıla paralel olarak artan konut ihtiyacı, yapı malzemesi talebini arttırmış; ancak gerek savaş nedeniyle yapı malzemesi ithalatının neredeyse durmuş olması, gerekse mevcut fabrikaların üretiminin azalması sonucunda piyasada yapı malzemesi bulunmaz hale gelmiştir. Fabrikalarda yapı malzemelerinin üretim miktarları sürekli azalmakta; talep arttıkça da, satış birlikleri nedeniyle sürekli artma eğilimindeki yapı malzemesi fiyatlarında daha da büyük artş̧lar meydana gelmektedir. Öyle ki, 1943 yılında çimentonun fiyatı neredeyse iki katına yükselmesine rağmen; fabrikalar hala yeterli üretimi sağlayamadıkları gibi, çimento almak için fabrikalara ödeme yapan müteahhitlere de, ne çimento verilebilmekte ne de geri ödeme yapılmaktadır. ${ }^{66}$ Fiyatların artması ve özel inşaat sahiplerine çimento verilmemesi sonucunda, özellikle İstanbul'da kamuya ait olmayan yatırımların hemen hepsi neredeyse durma noktasına gelir. ${ }^{67}$

Bu dönemde, sadece çimento değil, bütün yapı malzemelerinin üretilmesinde ve temin edilmesinde sıkıntilar yaşanmaktadır. Ülkedeki yapı malzemesi endüstrisinin sorunları yalnızca çimento ve demir fabrikalarının sayıca ve üretim kapasitesi bakımından yetersizliği ile sınırlı değildir; aynı zamanda kereste, tuğla, kiremit fabrikalarının ilkel teknolojilerle çalışmaları ve düşük kalitede üretim yapmaları, taş ve mermer ocaklarının da makineler yerine yalnızca insan emeğiyle çalışması, ${ }^{68}$ bunun yanı sıra, Almanya ile ilişkilerin kesilmesi, Amerika ve İngiltere gibi ülkelerden de ithal etme olanağının bulunmaması nedeniyle, yerli üretimi olmayan özellikle çinko, çivi, fayans, vb. gibi yapı malzemelerinin büyük ölçüde temin edilememesi ${ }^{69}$ gibi sorunlar da yaşanmaktadır. Dolayısıyla, yapı malzemesi üretimi ve ithalat yetersiz olduğu gibi, üretilen yapı malzemeleri kalite açısından da sorunludur. Yapı malzemeleri ile ilgili standartların belirlenmesine yönelik bazı çalışmalar yapılmışsa $\mathrm{da},{ }^{70}$ mevcut durumda bir iyileştirme sağlanamamıştr.

Tüm dünyada yaşanan olumsuz ekonomik koşullar, ithalatla varlığını devam ettiren yapı malzemesi sektöründe de etkili olarak, bu yılların yapı üretimi etkinliği ve mimarlık

\footnotetext{
${ }^{66}$ Anonim, 1943a, s. 94.

${ }^{67}$ Anonim, 1941, s. 284.

${ }^{68}$ Mortaş, 1943, s. 51-53.

${ }^{69}$ Anonim, 1944, s. 240-241.

70 iktisat Vekâleti Standardizasyon

Şubesi tarafindan, tuğla ve kiremit gibi yapı malzemelerinin standartlarını ve ebatlarını belirleyen talimatnameler hazırlanması (Anonim, 1940 , s. 279) bunlar arasında sayılabilir.
} 
ortamını şekillendirir. Sürdürülmekte olan veya zorunlu yatırımlar arasında olan devlet inşaatları dışındaki tüm inşaat projelerinin ertelenmek veya yavaşlatılmak zorunda kalındığı bu süreç, aynı zamanda tüm yatırımların askıya alınarak, devletin ekonomideki etkinliğini arttırma amaçlı bir takım tedbirlerin geliştirmesini de beraberinde getirir. $^{71} \mathrm{Bu}$ tedbirlerin en önemlilerinden biri, her ne kadar Türkiye savaş dışında kaldıysa da, bütçenin çoğunluğunun savunma masraflarına ayrılmasıyla ortaya çıkan ekonomik sıkıntılar ve belirsizlik ortamında, devlet gelirlerine ek kaynak yaratmak amacıyla, 11 Kasım 1942 tarihinde, "servet ve kazanç sahiplerinin servetleri ve fevkalade kazançları üzerinden alınmak ve bir defaya mahsus olmak üzere varlık vergisi adıyla bir mükellefiyet"72 olan 4305 sayılı Varlık Vergisi Kanunu'nun çıkarılmasıdır. Özellikle yapı malzemesi endüstrisini doğrudan etkileyecek bir diğeri tedbir ise, sanayi ve maden kuruluşlarının üreteceği ürün ve miktarın devlet tarafindan belirleneceği, gerekli yatırımların devlet izni ve denetimine bağlı olacağı, bu tedbirlere ayak uyduramayan kuruluşlara uygun bir tazminat ödenerek devlet tarafindan el konulabileceği ve işletilebileceği kararlarını içeren 1940 tarihli Milli Koruma Kanunu'dur. ${ }^{73}$ Böylelikle, aşırı kazancı -vurgunları ve karaborsayı- önleme amaçlı bu politikalarla, ekonomiye yönelik devlet müdahaleleri büyük ölçüde arttırılmış ve tüketim mallarının devlet eliyle dağıtılmasına başlanmıştr. ${ }^{74} \mathrm{Ne}$ yazık ki, bu uygulamalarla da karaborsanın varlığı engellenememiş ve bu kanun, 1942 yılında, herhangi bir koşula bağıı olmaksızın, devletin sanayi ve maden işletmelerine, görülen lüzum üzerine el koyabileceği biçiminde yeniden düzenlenmiştir. ${ }^{75}$

1943 yılında, öngörülen liberal ekonomi politikaları kapsamında fiyatların serbest bırakılmasıyla, yapı malzemelerinin satış fiyatları en yüksek seviyeye çıkmış, aynı yıl Bakırköy Çimento Fabrikası'na, "görülen lüzum üzerine" devlet tarafindan el konulmuştur. ${ }^{76}$ Diğer taraftan, aynı yıl, Sümerbank tarafindan 1939 yılında yapımına başlanan Sivas Çimento Fabrikası üretime başlamışsa da, ihtiyacı karşılamakta yetersiz kalmıştr. İç ve Doğu Anadolu'daki çimento ihtiyacını kısmen de olsa gidereceği öngörülen bu fabrikada üretilen çimento fiyatları, nakliye masrafları nedeniyle, İstanbul'daki fabrikalardan daha yüksek olduğundan, ${ }^{77}$ çimento piyasasındaki karaborsanın varlığını engelleyememiştir. Hatta, çimento karaborsasının varlığı artarak devam etmiş ve 1947 yılında öyle bir hal almıştır ki, İktisat Vekâleti tarafindan çimento satşları hakkında yeni bir kararname çıkartılarak çok sıkı bir denetim altına alınmış ve çimento dağıtımı valilik ve kaymakamlıklara bağlanmıştır. ${ }^{78}$ Ancak,

\footnotetext{
${ }^{71}$ Avcıoğlu, 1996, s. 464-465; Batur, 1998 , s. 228-229.

8, İçtima 1, 18.01.1940

74 Yücel, 2015, s. 44

72 "Varlık Vergisi Hakkında Kanun La- 75 Avcıoğlu, 1996, s. 464-465. yihası", TBMM Zabıt Ceridesi, Devre ${ }^{76}$ Anonim, 1943c, s. 188.

3 "Milli Korunma Kanunun Layihası", 77 Anonim, 1943b, s. 141.

TBMM Zabıt Ceridesi, Devre VI, Cilt ${ }^{78}$ Anonim, 1947, s. 102.
}

bu tedbirler de üretim etkinliğinin arttrılması ve yapı malzemelerinin temini için çözüm olmamıştır.

Savaş yıllarında, dünya ekonomisindeki durgunlukla bağlantılı olarak, içe dönük bir sürecin yaşanması ve ithalat olanaklarının azalmasıyla, yeni yatırımlar yapılamadığı gibi, üretimde kullanılan makine ve araçlar da yenilenememiş, ve böylelikle sanayi sektöründe önemli gelişmeler kaydedilmemiştir. Ancak, savaşın 1945 yılında sona ermesiyle birlikte, yabancı sermayeye ve dış yardımlara dayalı yeni bir döneme girilir. ${ }^{79}$ Bu bağlamda, 24 Ekim 1945'te, Birleşmiş Milletler Örgütü'nün kuruluşu, ${ }^{80}$ ekonomi ve sanayi alanında önemli bir kırılma noktası tanımlar. Böylelikle, ülkede halen üretimi yapılamayan veya yeterli olmayan yapı malzemeleri tekrar büyük oranda ithal edilmeye başlanır.

1946 yılında tek partili dönemden çok partili döneme geçilmesi ve savaş yıllarında yaşanan ekonomik zorluklar, savaşın sona ermesiyle beraber liberal ekonomi yaklaşımının benimsenmesine neden olacaktır. Bu kapsamda, 1947 yılında Truman Doktrini ve 1948 yılında da Marshall Yardım Programı çerçevesinde ABD'den alınan ekonomik yardımlar, sonraki yatırım ve gelişim politikalarını belirleyecektir. Cumhuriyet Halk Fırkası tarafindan, 1947 yılında, dış yardım alınacağı öngörüsüyle, tarım, haberleşme, enerji, demir-çelik, çimento, maden ve sanayi alanlarında gelişmeyi sağlamak amacıyla bir plan hazırlanmışsa da, bu planın kapsamlı biçimde uygulanması, ancak 1950 yılında başlayan Demokrat Parti yönetiminde gerçekleştirilecektir. ${ }^{81}$ Böylelikle, 19231931 yılları arasındaki liberal dönemi takip eden, 19321945 yılları arasındaki devletçilik dönemi yerini liberal ekonominin belirlediği bir döneme bırakacaktır. ${ }^{82}$

\section{Sonuç Yerine}

Mimari üretimdeki en önemli girdilerden birini tanımlayan yapı malzemesi endüstrisinin, erken Cumhuriyet yıllarındaki mimarlık etkinlikleri ve yapı üretimindeki belirleyici rolünün tartş̧ıldığı bu makale ile birlikte; yalnızca teknolojik ürünler olmaktan öte bir anlam taşıyan yapı malzemelerinin, mimari kültür ve üretim ortamı ile olan karşılıklı ilişkilerine dikkat çekilmiş (Şekil 7) ve böylelikle mimarlık alanında kuramsal tartışmalara da konu olabileceği ortaya konmak istenmiştir.

Cumhuriyet'in ilanıyla birlikte benimsenen çağdaşlaşma ideali, toplumsal, kültürel, ekonomik ve politik olmak üzere, her alanda köklü değişimlere yol açmış; mimari üretim ve kültür ortamı kadar, bir sanayi ülkesi olma tahayyülü de, radikal bir modernleşme projesine dönüşen bu idealin somutlaşttğı en önemli alan olmuştur. Bu kapsamda, başta Ankara olmak üzere, tüm Anadolu kentlerinde modernliğin simgeleri olacak -sanayi tesisleri, halkevleri, sağlık ve eğitim yapıları, modern konutlar vb. gibi- yapıların inşa-

\footnotetext{
79 Avcıoğlu, 1996, s. 504.

${ }^{80}$ Yücel, 2015, s. 49
} 





sıyla kapsamlı imar faaliyetlerinin başlatılması, yapı malzemelerine yönelik talebi artırmış; Cumhuriyet Türkiyesi'nin, imparatorluktan devralmış olduğu kısıtlı ve gelişmemiş yapı malzemeleri endüstrisi, Cumhuriyet'in sanayileşme politikaları kapsamında yapılandırılmaya ve geliştirilmeye çalışıımıştır.

Ancak, kamu kaynakların kısıtlı olması sebebiyle, yapı malzemeleri endüstrisinin gelişimine bu kaynakların oldukça az bir kısmını yönlendirebilen devlet, bu alanı büyük oranda özel girişimlere bırakmak zorunda kalmıştır. Bu yıllarda, devralınan sanayinin yetersizliği nedeniyle, daha çok ithalata bağımlı olan sanayi alanında, yerli üretimi ve yerli üreticiyi destekleme amacıyla çıkarılan Teşvik-i Sanayi Kanunu, yapı malzemesi endüstrisindeki özel girişimlerin varlığını daha da arttırmış; böylelikle özel girişimler, yapı malzemesi üretiminde en etkin aktör haline gelerek, piyasayı geniş ölçüde yönlendirmiştir. Bu yıllarda yapı üretim etkinliğindeki bir diğer önemli gelişme ise, yeni başkent Ankara'nın kurumsallaşmasının ön plana alınması nedeniyle, inşai faaliyetlerin kamuya ait, büyük ölçekli yapılara odaklanmasıdır. Dolayısıyla, yapı malzemesi endüstrisinin en büyük müşterisi devlettir ve ülkeye davet edilen yabancı mimarların kısmen ve/veya tamamen betonarme sistemde inşa ettiği modern üslüptaki yapılar, 1927 öncesi dönemdeki büyük ölçüde kâgir ve Osmanlı üslubunda inşa edilmiş yapı üretim etkinliğinden farklılaşmaktadır.

Dünya Ekonomik Bunalımı'nın da etkileriyle, her alandaki gelişmenin devlet eliyle sağlanması görüşüne dayanan devletçilik ilkesinin kabul edilmesi ve bu kapsamda Birinci Beş Yıllık Kalkınma Planı'nın oluşturulması, her alanda olduğu gibi, yapı üretimi ve yapı malzemesi endüstrisinde de belirleyici olmuştur. Her ne kadar, yapı malzemesi endüstrisi bu planın merkezinde yer almamış ve yapı malzemesine yönelik üretim tesisleri büyük ölçüde özel girişimlere bırakılmışsa da; yerli sanayinin geliştirilmesi amacıyla ithalatta kısıtlamaya gidilmesi, hammaddelerin devlet tarafindan sağlanması, yapı malzemelerine yönelik standartların getirilmesi gibi, devletin sektör üzerindeki çeşitli müdahaleleri, yapı malzemesi endüstrisini doğrudan etkilemiş; bu müdahalelerin en önemli sonuçlarından biri ise özel girişimlerin satş̧ birlikleri oluşturarak, piyasayı yönlendirmeleri olmuştur.

Bu dönemde büyük ölçüde yabancı mimarların üstlendiği, modernist bir üslup çerçevesinde biçimlenen ve betonarme yapım sistemine dayanan inşai faaliyetler, özellikle de çeşitli Anadolu kentlerinde gerçekleştirilen büyük ölçekli sanayi tesisleri ve bu tesislerin büyük kapasiteli yerleşkeleri, büyük oranda çimento ve demir gibi malzemelerin kullanılmasına intiyaç duymaktadır. Ancak, yapı malzemesine yönelik tesislerin üretim kapasiteleri, bu kapsamlı imar faaliyetlerinin gerektirdiği intiyacı karşılamakta yetersiz kaldığı gibi, malzeme standartları oldukça düşük, ancak fiyatları da bir o kadar yüksektir. Bunun yanı sıra, birçok yapı malzemesinin kullanımı, ülke içinde üretimleri yapılmadığından ithalata bağımlıdır. Yapı malzemelerinin üretim, dağıtım, fiyat ve standartlarına yönelik gerçekleştirilen çeşitli devlet müdahaleleri bu sorunların çözümünde yetersiz kalmış; yapı malzemesi alanında ne üretim kapasitesi, ne malzeme standartları, ne de üretim çeşitliliği açısından önemli gelişmeler kaydedilememiştir. Bu kapsamda, Cumhuriyet ideolojisinin somutlaştĭg yapı üretimi ve imar faaliyetleri, benimsenen modernleşme idealinin simgeleri olmakla birlikte, kısıtlı imkanlarla sürdürülen bir yapı malzemesi endüstrisine rağmen gerçekleştirilmiştir.

Yapı malzemesi endüstrisinin durumu, 1930'lu yılların ortalarından itibaren, devletin sektöre müdahalesini de beraberinde getirmiş; devletçilik anlayışı her alanda olduğu gibi, hem yapı malzemesi endüstrisinde, hem de yapım etkinliklerinde belirleyici olmuştur. 1940 'lar ise, 2. Dünya Savaşı'nın yaratth̆ı koşullar nedeniyle, hem yapı malzemesi endüstrisinin, hem de imar ve yapım faaliyetlerinin "askıya alındığı" yıllardır. Bu dönemde, ithalata bağlı olarak varlığını sürdüren yapı malzemesi fabrikaları, faaliyetlerini durdurmak zorunda kalmış; bunun paralelinde ülkedeki imar ve yapım faaliyetleri neredeyse tamamen durmuştur. 1930 'lardan beri sürdürülen devletçi politikaların yerine 1940 'ların ortalarında benimsenen liberal politikalarla beraber, hareketlenmeye başlayan ekonomi piyasalarının ve ithalatının, yapı malzemesi endüstrisi ve bağlantılı olarak inşai faaliyetler üzerindeki etkisinin sonuçları ise somut olarak ancak 1950'lerde görülebilecektir.

\section{Kaynaklar}

Alpagut, L. (2015). "Cumhuriyetin Mimarı Ernst Arnold Egli”, Mimarlık, sayı 383.

Anonim (1934a) "Haberler", Arkitekt, Sayı 6, s.190.

Anonim (1934b) "Haberler", Arkitekt, Sayı 7, s.222.

Anonim (1935a) "Duyumlar", Arkitekt, Sayı 6, s.155.

Anonim (1935b) "Duyumlar", Arkitekt, Sayı 11-12, s.358.

Anonim (1936a) "Duyumlar", Arkitekt, Sayı 8, s.243.

Anonim (1936b) "Duyumlar", Arkitekt, Sayı 9, s.273.

Anonim (1936c) "Malzeme Fiyatlarında Yükselme", Arkitekt, Sayı 9, s.273.

Anonim, (1937a) "Duyumlar", Arkitekt, Sayı 1, s.30.

Anonim, (1937b) "Duyumlar", Arkitekt, Sayı 2, s.62.

Anonim (1937c) "Duyumlar", Arkitekt, Sayı 10-11, s.313.

Anonim (1938) "Duyumlar", Arkitekt, Sayı 9, s.276.

Anonim (1940) "Haberler", Arkitekt, Sayı 11-12, s. 279.

Anonim (1941) "Haberler", Arkitekt, Sayı 11-12, s.284.

Anonim (1943a) "Haberler", Arkitekt, Sayı 3-4, s.94.

Anonim (1943b) "Haberler", Arkitekt, Sayı 5-6, s.141.

Anonim (1943c) "Haberler", Arkitekt, Sayı 7-8, s.188.

Anonim (1944) "Inşaat Malzemesi Fiyatları”, Arkitekt, Sayı 9-10, s.240-241.

Anonim (1947) "Haberler”, Arkitekt, Sayı 3-4, s. 102.

Aslanoğlu, İ. (2010) Erken Cumhuriyet Dönemi Mimarlığı 19231938, İstanbul, Bilge Kültür Sanat. 
Avcıoğlu, D. (1996) Türkiye'nin Düzeni (Dün-Bugün-Yarın), Birinci Kitap, İstanbul, Tekin Yayın Evi.

Batur, A. (1998) "1925-1950 Döneminde Türkiye Mimarlığı”, Ed: Yıldız Sey (editör) 75 Yılda Değişen Kent ve Mimarlık, İstanbul, Tarih Vakfi Yayınları, s.209-234.

BCA, 30-18-1-1/13-31-15, 13.05.1925.

BCA, 30-18-1-1/17-89-1, 31.01.1926.

BCA, 30-18-1-1/18-28-11, 04.05.1926.

BCA, 30-18-1-1/ 24-30-4, 11.05.1927.

BCA, 30-18-1-2/9 -11-5, 12.03.1930.

BCA, 30-18-1-2/9-20-6, 09.04.1930.

BCA, 30-18-1-2/20-40-8, 07.06.1931.

BCA, 30-18-1-2/ 71-10-3, 02.02.1937.

Birben, Ü. (2008) "Türkiye'de 1937 Yılından Sonra Ormancılık Mevzuatında Yaşanan Gelişmeler ve Toplumsal Yaşamla Etkileşimler", İstanbul Üniversitesi Orman Fakültesi Dergisi, Cilt 58 , Sayı 1, s. 1-16.

Bozdoğan, S. (2002) Modernizm ve Ulus'un İnşası: Erken Cumhuriyet Türkiyesi'nde Mimari Kültür, İstanbul, Metis.

Doğan, M. (2013) "Türkiye Sanayileşme Sürecine Genel Bir Bakış", Marmara Coğrafya Dergisi, Sayı 28, s.211-231.

Dölen, E. ve Koraltürk, M. (2004) İlk Çimento Fabrikamızın Öyküsü 1910-2004, İstanbul, Türkiye Ekonomik ve Toplumsal Tarih Vakfi Yayınları.

Geray, U. \& Ok, K. (2001) "Türkiye Cumhuriyeti Devletinin Kalkınma Hareketleri ve Sektörel Gelişmeler: Ormancılık", Türk Dünyası Kültür Atlası, İstanbul: Türk Kültürüne Hizmet Vakfi.

Gümüş, C. (2014) “Osmanlıdan Günümüze Ormancılık Politikalarının Ormancılık Örgütlenmesi Üzerine Etkileri ve Güncel Sorunlar", II. Ulusal Akdeniz Orman ve Çevre Sempozyumu, 22-24 Ekim 2014, Isparta, s.477-488.
Mortaş, A. (1943) "Yapı Sanayii”, Arkitekt, Sayı 3-4, s. 51-53.

Özgüven, Y. (2002) "Türkiye'de Kadın Mimar Kariyerinin Başlangıcı (1934-1960)", Yüksek Lisans Tezi, Yıldız Teknik Üniversitesi Fen Bilimleri Enstitüsü.

Selah, Z. (1934) "Türkiye'de Çimento Bir Lükstür", Arkitekt, Sayı 5, s.155.

Sey, Y. (1998) “Cumhuriyet Döneminde Türkiye'de Mimarlık ve Yapı Üretimi”, Ed: Yıldız Sey (editör) 75 Yılda Değişen Kent ve Mimarlık, İstanbul, Tarih Vakfi Yayınları, s.25-39.

Sey, Y. (2003) Türk Çimento Tarih, İstanbul, TÇMB ve ÇMis Yayınları.

TBMM Zabıt Ceridesi, Milli Korunma Kanunun Layihası, Devre VI, Cilt 8, İçtima 1, 18.01.1940.

TBMM Zabıt Ceridesi, Varlık Vergisi Hakkında Kanun Layihası, Devre VI, Cilt 28, İçtima 4, 11.11.1942.

Tekeli, İ. (2009) “Modernleşme Sürecinde İstanbul'un Nüfus Dinamikleri Nasıl Değerlendirilmeli?", Ed: Murat Güvenç (editör) Eski İstanbullular Yeni İstanbullular, İstanbul, Osmanlı Bankası Arşiv ve Araşttrma Merkezi, s.11-34.

Yılmaz, M. E. \& Çügen, H. F. (2011) “Hıfzıssıhha Enstitüsü Kimyahane ve Bakteriyoloji Binası'ndan Sağlık Müzesi ve Kütüphanesi'ne", Mimarlık, sayı 361.

Yurtoğlu, N. (2015) "Kalkınmanın Önemli Bir Unsuru, Kuruluşundan 50. Yılına Türkiye'de Çimento Sanayi (1910-1960)", Atatürk Kültür, Dil ve Tarih Yüksek Kurumu Atatürk Araştirma Merkezi Dergisi, Cilt: XXXI, Sayı: 92, s. 113-164.

Yücel, F. (2014) Cumhuriyet Türkiyesi'nin Sanayileşmede Illk Önemli Adımı: Birinci Beş Yıllık Sanayi Planı 1934-1938, Ankara, TMMMOB Elektrik Mühendisleri Odası.

Yücel, F. (2015) Cumhuriyet Türkiyesi'nin Sanayileşme Öyküsü, Ankara, Türkiye Teknoloji Geliştirme Vakfi. 